\title{
Effect of 12 Weeks of Intense Endurance Training and Bee Pollen Consumption on ABCA1 Gene Expression in Small Intestine, Liver and Gastrocnemius Muscle of Male Rats
}

\author{
Amir Taghipoor Asramy (PhD \\ candidate) \\ Department of Biochemistry, Faculty \\ of Physical Education and Sport \\ Sciences, University of Mazandaran, \\ Mazandaran, Iran \\ Abbas Ghanbari-Niaki (PhD) \\ Department of Exercise Biochemistry, \\ Faculty of Physical Education and \\ Sport Sciences, University of \\ Mazandaran, Mazandaran, Iran \\ Shirin Hakemi (PhD) \\ Department of Clinical Biochemistry, \\ Shahid Beheshti University of Medical \\ Sciences, Tehran, Iran \\ Mehran Naghizadeh Qomi (PhD) \\ Department of Statistics, Faculty of \\ Mathematics, University of \\ Mazandaran, Mazandaran, Iran \\ Mohammad Mehdi Moghanny Bashi \\ (PhD) \\ Department of Genetics, Faculty of \\ Medicine, Kazeroon Branch, Islamic \\ Azad University, Kazeroon, Iran \\ Corresponding author: Abbas \\ Ghanbari-Niaki \\ Email: ghanbara@umz.ac.ir \\ Tel:+9891313314878
}

Address: University of Mazandaran, Mazandaran, Iran

Received : 16 Oct 2016

Revised: 02 Nov 2016

Accented: 26 Nov 2016

\section{ABSTRACT}

Background and Objectives: The aim of this study was to evaluate the effect of 12 weeks of intense endurance training and bee pollen consumption on $A B C A l$ gene expression in small intestine, liver and gastrocnemius muscle tissues of male rats.

Methods: In this study, 24 male Wistar rats (aged 6-8 weeks and weighing 90-110 g) were randomly divided into four groups of saline-control $(n=6)$, saline-training $(n=6)$, bee pollen-control $(n=6)$ and bee pollen-training $(n=6)$. The training groups exercised on a treadmill for 12 weeks $(30 \mathrm{~m} / \mathrm{min}, 90 \mathrm{~min} /$ day, five days/week). The bee pollen groups were given bee pollen orally $(500 \mathrm{mg} / \mathrm{Kg})$ for 12 weeks. Data were analyzed using two-way AN0VA at significance level of 0.05 .

Results: $A B C A 1$ gene expression was highest in the liver, gastrocnemius muscle and small intestine, respectively. The findings also revealed that the intense endurance training caused a non-significant increase in $A B C A 1$ gene expression in the small intestine and liver. However, the training caused a non-significant decrease in $A B C A 1$ gene expression in the gastrocnemius muscle. In addition, consumption of bee pollen significantly increased ABCAI gene expression in the small intestine and gastrocnemius muscle of male rats. However, the effect of bee pollen on the gene's expression in the liver was not statistically significant.

Conclusion: Based on our findings, it can be concluded that consumption of bee pollen has more beneficial effects on the ABCAl gene expression and reverse cholesterol transport compared with the intense endurance training.

Keywords: ABCAl protein, Pollen, exercise.

This paper should be cited as: Ghanbari-Niaki A, Hakemi SH, Naghizadeh Qomi M, Moghanny Bashi MM[Effect of 12 Weeks of Intense Endurance Training and Bee Pollen Consumption on ABCA1 Gene Expression in Small Intestine, Liver and Gastrocnemius Muscle of Male Rats]. mljgoums. 2018; 12(1):11-16 


\section{INTRODUCTION}

Cardiovascular disease is the leading cause of death in industrialized countries. Fat gain, especially cholesterol, can be an important factor in worsening of the disease (1). In addition, coronary heart disease is directly influenced by high levels of lowdensity lipoprotein cholesterol (LDL-C) and has an inverse correlation with elevated levels of high-density lipoprotein cholesterol (HDLC) (2). The preventive effect of HDL is attributed to its role in reverse cholesterol transport. ATP-binding cassette transporter A1 (ABCA1) is involved in the reverse cholesterol transport by facilitating cholesterol efflux from cells to the receptor of lipid-poor apolipoprotein A-I particles, which is then delivered to the liver for excretion as bile salts. Since Apo AI has been shown to bind specifically to ABCA1, the lipid-poor apo A-I (pre $\beta$-HDL) acts as a cholesterol and phospholipid receptor in an ABCA1dependent manner, thus forming mature cholesteryl ester-rich spherical $\alpha$-HDL particles following the lecithin cholesterol acyl-transferase enzyme activity (LCAT) (37). The health benefits of training, particularly on the cardiovascular system, have been well demonstrated. Researchers have shown that physical activity have beneficial effects on lipoprotein profile by reducing level of triglycerides, LDL and VLDL and increasing the level of HDL (8). Physical activity also improves some of the key processes involved in the reverse cholesterol transport, by increasing HDL composition (8), cholesterol efflux (9), APO-1 formation (10, 11), plasma pre $\beta$-HDL level $(12,13)$ and activity of $\operatorname{LCAT}(10,14,15)$.

Since the discovery of the inverse relationship between HDL-C level and risk of cardiovascular disease, the origin of plasma HDL has been studied extensively. Moreover, several attempts have been made to raise plasma HDL levels and find the nature of HDL. The findings of these studies suggest that $\mathrm{ABCA} 1$ is critical for maintaining plasma HDL levels in rats. In addition, ABCA1 can be expressed in all body tissues, while only the small intestine and liver are able to produce APOA-1. Rats with gastrointestinal problems have significantly reduced amount of plasma HDL-C and HDL (5-7).

Khabazian et al. showed that short-term endurance training significantly increases
$A B C A 1$ gene expression compared to a control group $(16,17)$. In addition, Ghanbari-Niaki stated that long-term endurance training improves $A B C A 1$ gene expression in the heart and gastrocnemius muscle of rats (18). Wellington et al. investigated the level of mRNA and ABCA1 in various tissues of rats and then divided them into three groups. The $A B C A 1$ gene expression was highest in the liver, kidneys, adrenal glands, heart, bladder, testes and brain; moderate in the lung, adipose tissue, esophagus, stomach and small intestine; and lowest in colon, skeletal muscle, thymus and spleen (19).

Over the past few decades, alternative therapies, especially herbal medicine and dietary supplementation has become more popular for treatment of several diseases including hyperlipidemia (20). Honey is a natural product that has been widely used for its therapeutic effects for almost 5,000 years. The use of honeybee and related products such as honey, venom, propolis, bee pollen and royal jelly became more popular in the $20^{\text {th }}$ century (21). Bee pollen nutritional profile is one of the most complete in the world. To this day, 200 substances including proteins, amino acids, carbohydrates, lipids, fatty acids, phenolic compounds, enzymes, co-enzymes and vitamins have been found in bee pollen from different plant species $(20,22,23)$.

Experimental studies on rats and rabbits have demonstrated that bee pollen has lipid lowering activity and causes a decrease in level of plasma lipids and triglycerides. Moreover, bee pollen has been reported to increase HDL and reduce LDL level. Clinical studies confirm that bee pollen causes serum lipids loss, 20-35\% decrease in blood lipids and cholesterol and $30 \%$ reduction in platelet aggregation, and improves atherosclerosis (24). The liver and gastrocnemius muscle can use lipids as primary fuel during rest and prolonged endurance activity. In the human body, cholesterol is mainly synthesized by the small intestine (18). Bee pollen offers $15 \%$ lecithin by volume, which is thought to increase metabolic rate (25). There is currently no study available on the role of training along with bee pollen supplementation in the mechanism of reverse cholesterol transport. Therefore, this study was conducted to determine the effect of 12 weeks of intense endurance training and bee pollen 
consumption on $A B C A 1$ gene expression in the small intestine, liver and gastrocnemius muscle of male rats.

\section{MATERIAL AND METHODS}

In the present semi-experimental study, 24 white male Wistar rats aged 8 weeks (mean weight: $90 \pm 20 \mathrm{~g}$ ) were obtained from the Pasteur Institute of Amol, Iran. The rats were kept in a $6 \times 5$ meters room under 12:12-h light: dark cycle, at $22 \pm 3{ }^{\circ} \mathrm{C}$ and $45 \%$ humidity. One week was given to the subjects to become familiar with the laboratory environment and manipulations. Using simple random sampling, the subjects were divided into four groups of saline-control, bee pollen-control, saline-training and bee pollen-training. The rats in all groups were matched in terms of body weight.

The training groups exercised on a treadmill at intensity of $30 \mathrm{~m} / \mathrm{min}$, five days a week, for 12 weeks. The rats were subjected to run at low intensity $(15 \mathrm{~m} / \mathrm{min}$, for $20 \mathrm{~min})$, but later, speed and duration of exercise were gradually increased. In the first three weeks, the subjects were able to run at $30 \mathrm{~m} / \mathrm{min}$ for $90 \mathrm{~min}$, five days/week. The subjects ran on the treadmill at a fixed intensity and duration for the next nine weeks. Rats in the control group walked freely on a treadmill, three sessions per week, for 10 minutes (26).

Immediately after training, $500 \mathrm{mg}$ aqueous extract per $\mathrm{Kg}$ of body weight were administered orally to the rats in the control and bee pollen-training groups, five times a week for 12 weeks. Equal amount of saline solution (normal saline) was given to the saline group.

The rats were anesthetized $48 \mathrm{~h}$ after the last training session by intraperitoneal injection of ketamine $(80 \mathrm{mg} / \mathrm{Kg})$ and xylazine $(10 \mathrm{mg} / \mathrm{Kg})$ while fasting for three hours (water was available). Approximately $50 \mathrm{mg}$ of tissues were powdered by incubation. The powders were homogenized in $800 \mu \mathrm{L}$ of TRizol (Invitrogen, USA) for extraction of total RNA. The samples were centrifuged at $13000 \mathrm{~g}$ for $15 \mathrm{~min}$ at $4{ }^{\circ} \mathrm{C}$ to separate protein components and phenolic compounds. One $\mathrm{ml}$ of chloroform was added to the supernatant, and the mixture was vortexed for 15 seconds. The mixture was centrifuged again at the mentioned conditions. Mineral and aqueous phases were separated. The supernatant containing RNA was mixed with $800 \mu \mathrm{L}$ of isopropanol, and the mixture was incubated for $15 \mathrm{~min}$ at room temperature, and centrifuged at the mentioned conditions. The extracted RNA was dissolved in $50 \mu \mathrm{L}$ of RNAase-free water and stored at $-80{ }^{\circ} \mathrm{C}$ for future testing. RNA integrity was checked by agarose gel electrophoresis and detection of RNA band between $18 \mathrm{~s}$ and $28 \mathrm{~s}$. The RNA quality and concentration were assessed using Nanodrop (Pharmacia, Sweden), and absorption at ratio of 260/280 nm was between 1.6 and 1.8 for all samples.

All procedures were performed under a laminar hood (Zal Tajhiz Co., Iran) previously sterilized with alcohol (75\%) and UV. Revert Aid H Minus First Strand cDNA kit (Product code: K1631) was used for cDNA synthesis in a thermocycler (Bio Rad, USA), according to the manufacturer's instructions and using random hexamer primers. The relative mRNA level of $A B C A 1$ gene was measured in small intestine, liver and gastrocnemius muscle tissues by semi-quantitative RT-PCR (Bio Rad, USA). All samples were analyzed in duplicate. After obtaining the binary CT for each sample, mean values were determined. Data were entered into Microsoft Excel and the level of $A B C A 1$ expression was calculated according to delta-delta CT formula.

Data were analyzed in SPSS (version 20). Normality of data distribution was verified using the Shapiro-Wilk test. Levene's test was used to assess the equality of variances. Twoway analysis of variance and Scheffe post hoc test were used to evaluate differences between the groups. All statistical analyses were performed at $95 \%$ confidence level $(\mathrm{P}<0.05)$.

\section{RESULTS}

After the 12 weeks of intense endurance training, $A B C A 1$ gene expression increased in the small intestine tissues from the training group ( $\mathrm{P}>0.05)$. $A B C A 1$ gene expression in the small intestine of pollen-control group increased significantly compared to the control group (Figure 1).

Moreover, the training and bee pollen supplement had no statistically significant effect on the mRNA content of ABCA1 in the liver (Figure 1). Supplementation of bee pollen caused a significant increase in $A B C A l$ gene expression in gastrocnemius muscle, while the endurance training decreased $A B C A l$ gene expression in the gastrocnemius muscle $(\mathrm{P}>0.05)$. 
Figure 1- Real time PCR of Intestine, liver and gastrocnemius ABCA1 relative mRNA expression in Saline-Control (SC), SalineTraining (ST), Bee pollen-Control (BPC), and Bee pollen-Training (BPT) wild type male Rats Data expressed as mean \pm SE.

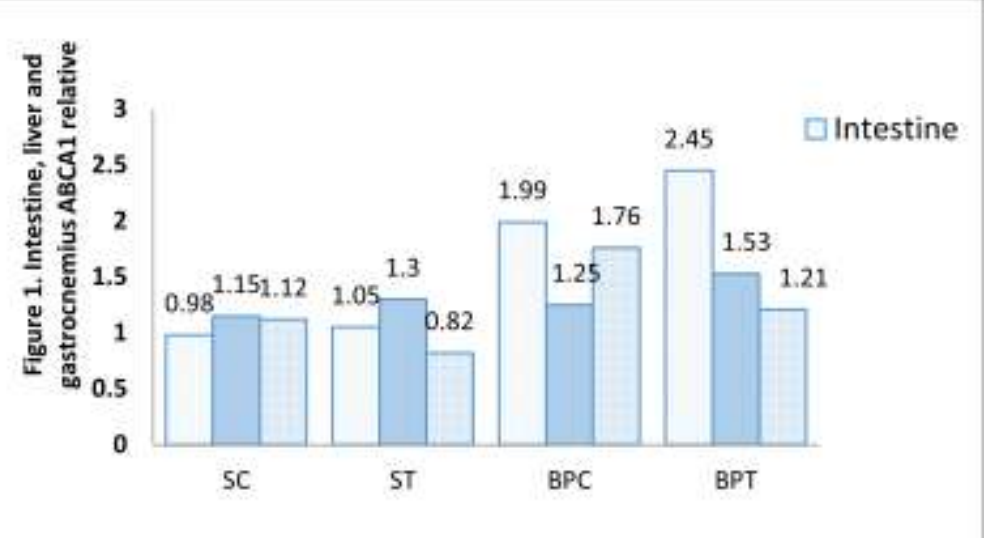

\section{DISCUSSION}

The results of the present study showed that the expression of $A B C A 1$ gene was highest in the liver, gastrocnemius muscle and small intestine of rats, respectively. However, there was no significant difference in the expression of $A B C A l$ gene between the study groups. This is somewhat similar to the findings of Farke et al., demonstrating that $A B C A 1$ gene expression is highest in the skeletal muscle, liver and small intestine of cows, respectively (27). It should be noted that the difference in $A B C A l$ gene expression between skeletal muscle and other tissues could be attributed to the structure of skeletal muscle (oxidative and glycolytic). However, our study investigated the male rat gastrocnemius muscle.

We detected a non-significant $A B C A 1$ overexpression in the small intestine following the intense endurance training. Although several studies have clarified the role of liver in the synthesis and expression of $A B C A 1$, few studies have investigated the level of $A B C A 1$ gene expression in the small intestine.

An investigation revealed that ABCA1 in the small intestine is responsible for about $30 \%$ of plasma HDL synthesis. ABCA1 in the small intestine is directly involved in conversion of cholesterol into HDL $(28,29)$. A study by Khabazian et al. showed that endurance training improves $A B C A l$ gene expression in the small intestine (17).

We found that supplementation of bee pollen significantly increased $A B C A 1$ gene expression in the small intestine. Empirical studies conducted on rats and rabbits show that pollen has lipid lowering activity, which can contribute to reduction of total lipid content and triglycerides (24). Bee pollen also reduces the level of hormones such as insulin and testosterone, which are responsible for lipid synthesis (23). In addition, bee pollen increases lipid efflux from adipose tissue because of its high niacin content. It also improves functional bowel disorders by reducing reactive oxygen species and elevating excess cholesterol efflux to macrophages via ABCA1 (30).

The intense endurance training and bee pollen supplementation caused a non-significant increase in $A B C A 1$ gene expression in the liver tissues. ABCA1 is largely expressed in the liver and has a key role in cholesterol and phospholipids efflux from the cells into lipidfree/lipid-poor apolipoproteins. Our findings are consistent with results of some previous studies (16). Based on our results, regular endurance training could increase $A B C A l$ gene expression in the liver of rats. Physical activity can elevate HDL and cause LXR and PPAR overexpression in the liver, which in turn regulate the $A B C A 1$ gene activity (31). On the other hand, high glucocorticoids and low insulin levels following long-term endurance activities promote $A B C A 1$ gene expression in hepatocytes.

The intense endurance training reduced $A B C A 1$ gene expression in gastrocnemius muscle. However, this effect was not statistically significant. In recent years, several studies have been conducted on the effects of exercise on ABCAl gene expression. According to these studies, endurance training increases $A B C A 1$ gene expression in the liver, small intestine and gastrocnemius muscle (32). Our results regarding the expression of $A B C A 1$ in the gastrocnemius muscle are inconsistent with findings of Ghanbari et al., which could 
be due to difference in the type of training and method of ABCAl expression assessment (semi-quantitative). It is also possible that another transporter, such as ABCG1 (unreported), is more active than ABCA1 in the gastrocnemius muscle (33). We demonstrated that taking bee pollen significantly improves $A B C A 1$ expression in the gastrocnemius muscle of male rats. It is well demonstrated that bee pollen has a beneficial role in skeletal muscle protein metabolism due to the synergistic effect of various nutrients such as leucine and antioxidants (34). Moreover, some of the components of pollen such as flavonoids increase gene expression and protein synthesis in muscle cells (35). In addition, bee pollen improves mitochondrial function in skeletal muscle by increasing citrate synthase (25). Although apoA1 cannot be expressed in the skeletal muscle (unreported), it can enter the skeletal muscle from other tissues. ApoA1/HDL ratio affects glucose uptake in skeletal muscles through ABCA1. Therefore, it can be concluded that ABCA1 is an important transporter in the reverse cholesterol transport from other tissues to the liver, and plays a role in activation of AMPK in skeletal muscles, which is essential for glucose homeostasis, lowering blood sugar and increasing lipid oxidation (33). On the other hand, bee pollen consumption caused a significant increase in expression of $A B C A 1$

\section{REFERENCES}

1. Hattori H, Kujiraoka T, Egashira T, Saito E, Fujioka $\mathrm{T}$, Takahashi S, et al. Association of coronary heart disease with pre- $\beta$-HDL concentrations in Japanese men. Clinical chemistry. 2004;50(3):589-95. DOI:10.1373/clinchem.2003.029207.

2. Drobnik W, Lindenthal B, Lieser B, Ritter M, Weber $\mathrm{TC}$, Liebisch $\mathrm{G}$, et al. ATP-binding cassette transporter A1 (ABCA1) affects total body sterol metabolism. Gastroenterology. 2001; 120(5):1203-11.

3. Oram JF. HDL apolipoproteins and ABCA1 partners in the removal of excess cellular cholesterol. Arteriosclerosis, thrombosis, and vascular biology. 2003; 23(5): 720-7.

4. Lewis GF, Rader DJ. New insights into the regulation of HDL metabolism and reverse cholesterol transport. Circulation research. 2005; 96(12): 1221-32.

5. Wang N, Silver DL, Thiele C, Tall AR. ATP-binding cassette transporter Al (ABCA1) functions as a cholesterol efflux regulatory protein. Journal of Biological Chemistry. 2001; 276(26): 23742-7. gene in the gastrocnemius muscle.

\section{CONCLUSION}

The intense endurance training could increase $A B C A 1$ gene expression in the small intestine and decrease the expression of the gene in the gastrocnemius muscle, but had no effect on the liver. Moreover, bee pollen consumption increases $A B C A 1$ gene expression in the small intestine and gastrocnemius muscle. Bee pollen also caused a non-significant overexpression in the $A B C A l$ gene in the liver.

It can be concluded that consumption of bee pollen has more beneficial effects on the $A B C A 1$ gene expression and reverse cholesterol transport compared with the intense endurance training.

\section{ACKNOWLEDGEMENTS}

This article is part of a $\mathrm{PhD}$ thesis entitled "Effects of 12 weeks of aerobic exercise and consumption of bee pollen on the expression of selected genes in the liver, small intestine and gastrocnemius muscle and tissue Sphingosine -1 phosphate rats" for completion of a course in Exercise

Physiology. The project has been supported by the Mazandaran University, Iran.

\section{CONFLICT OF INTEREST}

The authors declare that there is no conflict of interest.

6. Knight B. ATP-binding cassette transporter A1: regulation of cholesterol efflux. Biochemical Society Transactions. 2004; 32(1): 124-7.

7. Yancey PG, Bortnick AE, Kellner-Weibel G, de la Llera-Moya M, Phillips MC, Rothblat GH. Importance of different pathways of cellular cholesterol efflux. Arteriosclerosis, thrombosis, and vascular biology. 2003; 23(5): 712-9.

8. Durstine JL, Grandjean PW, Davis PG, Ferguson MA, Alderson NL, DuBose KD. Blood lipid and lipoprotein adaptations to exercise. Sports Medicine. 2001; 31(15): 1033-62.

9. Brites F, Verona J, De Geitere C, Fruchart J-C, Castro G, Wikinski R. Enhanced cholesterol efflux promotion in well-trained soccer players. Metabolism. 2004; 53(10): 1262-7.

10. Olchawa B, Kingwell BA, Hoang A, Schneider L, Miyazaki $\mathrm{O}$, Nestel $\mathrm{P}$, et al. Physical fitness and reverse cholesterol transport. Arteriosclerosis, thrombosis, and vascular biology. 2004; 24(6): 1087-91. 
11. Wilund KR, Colvin PL, Phares D, Goldberg AP, Hagberg JM. The effect of endurance exercise training on plasma lipoprotein AI and lipoprotein AI: AII concentrations in sedentary adults. Metabolism. 2002; 51(8): 1053-60.

12. Jafari M, Leaf DA, MacRae H, Kasem J, O'Conner P, Pullinger $\mathrm{C}$, et al. The effects of physical exercise on plasma prebeta-1 high-density lipoprotein. Metabolism. 2003; 52(4): 437-42. DOI:10.1053/meta.2003.50086.

13. Sviridov D, Kingwell B, Hoang A, Dart A, Nestel P. Single session exercise stimulates formation of preß1$H D L$ in leg muscle. Journal of lipid research. 2003; 44(3): 522-6. doi: 10.1194/jlr.M200436-JLR200.

14. KILINÇ C, YAĞMUR Z, YILMAZ K, KISA Ü. The Effects of exercise and smoking on serum lecithin: cholesterol acyltransferase activity in young men. Turkish Journal of Medical Sciences. 2000; 30(2): 161-6. 15. Tsopanakis C, Kotsarellis D, Tsopanakis A. Plasma lecithin: cholesterol acyltransferase activity in elite athletes from selected sports. European journal of applied physiology and occupational physiology. 1988;58(3):262-5

16. Ghanbari-Niaki A, Khabazian BM, Hossaini-Kakhak SA, Rahbarizadeh F, Hedayati M. Treadmill exercise enhances ABCA1 expression in rat liver. Biochemical and biophysical research communications. 2007; 361(4): 841-6.

17. Khabazian BM, Ghanbari-Niaki A, reza SafarzadehGolpordesari A, Ebrahimi M, Rahbarizadeh F, Abednazari H. Endurance training enhances ABCAl expression in rat small intestine. European journal of applied physiology. 2009; 107(3): 351-8.

18. Ghanbari-Niaki A. Treadmill exercise training enhances ATP-binding cassette protein-A1 (ABCA1) expression in male rats' heart and gastrocnemius muscles. Int J Endocrinol Metab. 2010; 8(4): 206-10.

19. Wellington CL, Walker EK, Suarez A, Kwok A, Bissada N, Singaraja R, et al. ABCA1 $\mathrm{mRNA}$ and protein distribution patterns predict multiple different roles and levels of regulation. Laboratory investigation. 2002; 82(3): 273-83.

20. ZENG Z-j, WANG L-gRB, FAN Z-b, XIE G-x. A Study on the Effect of Honeybee Pollen Polysaccharide on Decreasing Lipoidemia in Rat [J]. Acta Agriculturae Universitis Jiangxiensis. 2004; 3: 021.

21. Selmanoğlu G, Hayretdağ S, Kolankaya D, ÖzkökTüylü A, Sorkun K. The effect of pollen on some reproductive parameters of male rats. Pesticidi i fitomedicina. 2009; 24(1): 59-63.

22. Kolankaya D, Şentürkb H, Tüylü AÖ, Hayretdağ S, Selmanoğlua G, Sorkun K. The effect of Trifolium, Raphanus, and Cistus pollen grains on some blood parameters and mesentery mast cells. Zeitschrift für Naturforschung C. 2006; 61(5-6): 421-6.

23. Yildiz O, Karahalil F, Can Z, Sahin H, Kolayli S. Total monoamine oxidase (MAO) inhibition by chestnut honey, pollen and propolis. Journal of enzyme inhibition and medicinal chemistry. 2014; 29(5): 690-4. doi: 10.3109/14756366.2013.843171.

24. Selmanoğlu G, Hayretdağ S, Kolankaya D, Tüylü ÖA, Sorkun K. The effects of pollen on serum parameters, and liver and kidney tissues of rats. Pesticidi i fitomedicina. 2007; 22(1): 59-64.
25. Salles J, Cardinault N, Patrac V, Berry A, Giraudet $\mathrm{C}$, Collin M-L, et al. Bee Pollen Improves Muscle Protein and Energy Metabolism in Malnourished Old Rats through Interfering with the Mtor Signaling Pathway and Mitochondrial Activity. Nutrients. 2014; 6(12): 5500-16. doi: 10.3390/nu6125500.

26. Fathi R, Ghanbari-Niaki A, Rahbarizadeh F, Hedayati M, Ghahramanloo E, Farshidi Z. The effect of exercise on plasma acylated ghrelin concentrations and gastrocnemius muscle mRNA expression in male rats. Iranian Journal of Endocrinology and Metabolism. 2009; 10(5): 519-26.

27. Farke C, Viturro E, Meyer H, Albrecht C. Identification of the bovine cholesterol efflux regulatory protein ABCAl and its expression in various tissues. Journal of animal science. 2006; 84(11): 2887-94. DOI:10.2527/jas.2006-042.

28. Brunham LR, Kruit JK, Iqbal J, Fievet C, Timmins $\mathrm{JM}$, Pape TD, et al. Intestinal ABCAl directly contributes to $H D L$ biogenesis in vivo. The Journal of clinical investigation. 2006; 116(4): 1052-62.

29. Mulligan JD, Flowers MT, Tebon A, Bitgood JJ, Wellington C, Hayden MR, et al. ABCA1 is essential for efficient basolateral cholesterol efflux during the absorption of dietary cholesterol in chickens. Journal of Biological Chemistry. 2003; 278(15): 13356-66.

30. Kookandeh NZ, Deldar H, Niaki AG, Pirsaraei ZA, Ahmadabad SR, Raoof Z. ABCG1 gene responses to treadmill running with or without pistachio-atlantica in female rats. Iranian Journal of Health and Physical Activity. 2012; 3(1): 1-7.

31. Vosper H. Niacin: a re-emerging pharmaceutical for the treatment of dyslipidaemia. British journal of pharmacology. 2009;158(2): 429-41. doi: 10.1111/j.1476-5381.2009.00349.x.

32. Ghanbari-Niaki A, Ghanbari-Abarghooi S, Rahbarizadeh F, Zare-Kookandeh N, Gholizadeh M, Roudbari F, et al. Heart ABCAl and PPAR- $\alpha$ Genes Expression Responses in Male rats: Effects of High Intensity Treadmill Running Training and Aqueous Extraction of Black Crataegus-Pentaegyna. Research in Cardiovascular Medicine. 2013; 2(4): 153-9. doi: $10.5812 /$ cardiovascmed.13892.

33. Lehti M, Donelan E, Abplanalp W, Al-Massadi O, Habegger K, Weber J, et al. High-density lipoprotein maintains skeletal muscle function by modulating cellular respiration in mice. Circulation. 2013; 128(22): 2364-71. 10.1161/CIRCULATIONAHA.113.001551.

34. Feng X-T, Wang T-Z, Chen Y, Liu J-B, Liu Y, Wang $\mathrm{W}-\mathrm{J}$. Pollen Typhae total flavone improves insulininduced glucose uptake through the $\beta$-arrestin-2mediated signaling in C2C12 myotubes. International journal of molecular medicine. 2012; 30(4): 914-22. doi: 10.3892/ijmm.2012.1061.

35. Biolo G, Fleming RD, Wolfe R. Physiologic hyperinsulinemia stimulates protein synthesis and enhances transport of selected amino acids in human skeletal muscle. Journal of Clinical investigation. 1995; 95(2): 811-819. doi: 10.1172/JCI117731. 